\title{
Anchoring in financial decision-making: Evidence from Jeopardy!
}

Michael Jetter ${ }^{1} \&$ Jay K. Walker ${ }^{2}$

\begin{abstract}
This paper analyzes 12,596 Daily Double wagering decisions of 6,064 contestants in the US game show Jeopardy!. We exploit a situation in which a player has to, unexpectedly, wager on responding correctly to an unknown clue (known as a Daily Double clue). We find evidence consistent with the hypothesis of contestants anchoring heavily on the initial dollar value of a clue in wagering. This positive relationship remains statistically significant at the one percent level after controlling for other characteristics that may independently affect wagering decisions, such as scores, clue categories, time trends, individual Jeopardy! experience, and player-fixed effects. Exploiting within-player variation only, raising the anchoring amount by $\$ 100$ translates to an increase of $\$ 29$ in the wager. An alternative explanation of underlying strategic considerations appears unlikely and results are consistent throughout a number of robustness checks. Overall, these findings suggest that anchoring can play a substantial role in financial decision-making under pressure.
\end{abstract}

Keywords: anchoring, behavioral economics, financial decision-making, heuristics

JEL Classification: D03, D81, D83, G11

\footnotetext{
${ }^{1}$ University of Western Australia, IZA (Bonn), and CESifo (Munich); 35 Stirling Highway, Crawley, WA 6009, Australia. Email: mjetter7@gmail.com.

${ }^{2}$ Department of Economics, Old Dominion University, Constant Hall 2048, Norfolk, VA 23529, USA; E-mail: j1walker@odu.edu
} 


\title{
Anchoring in financial decision-making: Evidence from Jeopardy!
}

\begin{abstract}
This paper analyzes 12,596 Daily Double wagering decisions of 6,064 contestants in the US game show Jeopardy!. We exploit a situation in which a player has to, unexpectedly, wager on responding correctly to an unknown clue (known as a Daily Double clue). We find evidence consistent with the hypothesis of contestants anchoring heavily on the initial dollar value of a clue in wagering. This positive relationship remains statistically significant at the one percent level after controlling for other characteristics that may independently affect wagering decisions, such as scores, clue categories, time trends, individual Jeopardy! experience, and player-fixed effects. Exploiting within-player variation only, raising the anchoring amount by $\$ 100$ translates to an increase of $\$ 29$ in the wager. An alternative explanation of underlying strategic considerations appears unlikely and results are consistent throughout a number of robustness checks. Overall, these findings suggest that anchoring can play a substantial role in financial decision-making under pressure.
\end{abstract}

Keywords: anchoring, behavioral economics, financial decision-making, heuristics

JEL Classification: D03, D81, D83, G11

\section{Introduction}

Numerous studies suggest that as individuals make decisions, they tend to heavily rely on pieces of information they receive immediately beforehand (see Furnham and Boo, 2011, for an overview of the literature). Even arguably unrelated information can influence subsequent decisions. This phenomenon is now commonly known as "anchoring," following Tversky and Kahneman (1974). For example, participants in a laboratory experiment with higher social security numbers systematically report a greater willingness to pay for items such as a bottle of wine after their social security number has been made salient (see Ariely et al., 2003, or Beggs and Graddy, 2009, and List, 2011, for other examples). ${ }^{1}$ Further,

\footnotetext{
${ }^{1}$ Subjects were asked whether they would buy a bottle of wine (or, in other settings, goods like a cordless keyboard, a design book, or Belgian chocolates) for "a dollar figure equal to the last two digits of their social security number. After this Accept/Reject response, they stated their dollar maximum willingness-to-pay (WTP) for the product" (Ariely et al., 2003).
} 
anchoring has been found to matter for investment decisions, negotiating processes, reference pricing for consumers, and online auctions (e.g., see Galinsky and Mussweiler, 2001, and Furnham and Boo, 2011).

However, the anchoring phenomenon has been proven difficult to test in the field (see Furnham and Boo, 2011), as laboratory studies have provided the majority of evidence to date. Naturally, experimental settings are valuable in analyzing particular phenomena in a controlled, well-designed environment, but Levitt and List (2008) note that "[p]erhaps the greatest challenge facing behavioral economics is demonstrating its applicability in the real world." ${ }^{2}$ Our study aims to do exactly that for the anchoring phenomenon.

The following pages test the anchoring phenomenon in 6,064 contestants in one of the most popular game shows of all time: the US edition of Jeopardy!. The show provides an environment in which highstakes decisions have to be made quickly and under pressure. ${ }^{3}$ Our sample consists of 12,596 wagering decisions in Daily Double ( $D D$ from hereon) clues over 32 years. In every episode, three $D D$ clues are hidden among the 60 clues of the Jeopardy! and Double Jeopardy! rounds, prompting a high-stakes decision by the contestant who happens to (unknowingly) select a $D D$ clue. Our study uses the fact that contestants must select a clue that carries a certain dollar value (e.g., "I take Fonts for $\$ 1,600$ !") before they learn that they have selected a $D D$ clue. After that, the contestant can wager up to their entire account balance in correctly responding to the clue. ${ }^{4}$

This is precisely where anchoring may occur. Contestants are prepared to play for a clue of, say, $\$ 1,600$, but now they have to immediately decide how much of their current account balance they are willing to wager on their correctly answering of the clue. We posit that these dollar values serve as anchors for wagering decisions. Contestants $i$ ) are faced with an anchor, ii) have to make a financial decision that involves risk, iii) compete for substantial financial stakes, and $i v$ ) have to decide under substantial time pressure in a public forum. ${ }^{5}$

Our estimations suggest a positive and statistically meaningful link between the initial dollar value and the wagering amount. This finding is consistent with the anchoring hypothesis and remains robust to the inclusion of a comprehensive list of characteristics that may independently affect a player's wagering decision: the score relative to one's opponents, the maximum possible wager, the 20 most common clue categories, time trends, and player-fixed effects. The inclusion of fixed effects allows us to use within-player

\footnotetext{
${ }^{2}$ In this context, we also refer to Levitt and List (2007) and List and Millimet (2008) for discussions about the external validity of experimental studies.

${ }^{3}$ In addition to time pressure (having to make decisions within seconds), Jeopardy! contestants compete for high stakes and in front of a large audience: A winner of an episode usually earns US $\$ 19,752$ and, on average, Jeopardy! enjoys 25 million viewers per week (see Jeopardy!, 2015).

${ }^{4}$ At the time of wagering only the clue category is known, but the clue itself will only be revealed after the contestant wagers.

${ }^{5}$ Meub and Proeger (2015) propose that people tend to anchor more as the cognitive load increases.
} 
variation only, holding constant all unobservable characteristics that are specific to an individual, such as education, income, personality, cognitive ability, risk preferences, and Jeopardy!-specific knowledge. In terms of magnitude, an increase in the clue's initial dollar value by $\$ 100$ translates to a $\$ 29$ increase of the wagering amount.

We then conduct several robustness checks and extensions. Most importantly, we consider an alternative explanation of our finding, which is the hypothesis that contestants strategically choose their wagering amount rather than being driven by the anchor presented by the articulated dollar value of the clue. For instance, it is possible that selecting a clue value in the first place represents contestants' desire to play for that particular amount, potentially because of their score relative to opponents'. To isolate these aspects, we first analyze $D D$ clues that appear early in the show, where such strategies are less likely to play a role. In these cases, we also observe a strong relationship between the initial dollar value and the wager, providing support for the anchoring hypothesis.

Furthermore, we consider those clues where contestants follow a sequential choice of "going through" a particular category (e.g., choosing Fonts for $\$ 400$, followed by Fonts for $\$ 800$ ), where a strategic willingness to play for a specific dollar value appears less likely. Here again, our results prevail and are consistent with the anchoring hypothesis, whereas strategic considerations are unlikely to explain that result completely.

Finally, we test whether "institutional learning" has occurred (i.e., whether anchoring has become less prevalent since the show's inception and whether more recent contestants show different patterns) or whether successful Jeopardy! contestants are less prone to anchoring. However, we find little evidence of such dynamics, as our findings equally persist over the entire sample period, and winners of Jeopardy! episodes display the same patterns (which are consistent with the anchoring hypothesis) as non-winners.

Overall, these findings may help inform discussions on several common situations where anchoring may occur. For instance, high-stake investment decisions (e.g., stock market speculations or retirement planning) by individuals, CEOs, and major corporate decision-makers many times have to be made quickly and under pressure. Furthermore, betting markets, gambling decisions, negotiation processes, or online auctions may be influenced by anchors. Our results show that magnitudes may be economically sizeable.

The paper proceeds with providing a background of the anchoring literature, followed by a description of our data, the Jeopardy! setting, and our methodology. Section 4 presents our main findings, and Section 5 provides several robustness checks. Section 6 concludes. 


\section{A Brief Background of Anchoring}

In a seminal paper, Amos Tversky and Daniel Kahneman (1974) present results from several experiments, testing whether initial and even unrelated information can influence people's numerical answers to follow-up questions. Their key insights suggest that, in some situations, people seem to systematically anchor on information provided immediately prior to the respective question. Since then, a number of individual characteristics have been suggested to drive anchoring, such as cognitive ability, personality, or the Big Five personality traits (Furnham and Boo, 2011). For example, Bergman et al. (2010) find that anchoring is less pronounced for individuals with higher cognitive ability, whereas Frederick (2005) discusses how cognitive ability should influence economic decision-making in general.

Since the early 2000s, several studies have tested the phenomenon of anchoring in a range of situations. We want to briefly discuss some of these studies but do not claim to provide a comprehensive literature review here. First, in an experimental setting, Galinsky and Mussweiler (2001) find that first offers are a strong predictor of final settlement prices in negotiations, both in a face-to-face and an e-mail format. Also, Bucchianeri and Minson (2013) find evidence of anchoring in the US real estate market, in which higher starting prices are associated with higher selling prices.

Second, anchoring could be of substantial interest to the financial sector, where financial decisions can carry meaningful consequences. In an experimental setting, Kaustia et al. (2008) find that students and investment professionals anchor long-term expectations of stock returns on prior performance. Although diminishing with experience and expertise, this effect does not disappear. Other financial decisions where anchoring may play a role include credit card repayments (Stewart, 2009; Agarwal et al., 2015; Jones et al., 2015; McHugh and Ranyard, 2016), interest rates for borrowers (Dougal et al., 2015), merger and acquisition pricing (Baker et al., 2012), and contribution rates to retirement accounts (e.g., Choi et al., 2012). For instance, regarding credit card payments, Stewart (2009, p.40) find that "minimum-repayment information does reduce the size of partial repayments," which in turn reduces subsequent interest charges. Similarly, retirement account participation can be changed by introducing recommended savings rates that are higher or are making alternative choice sets more salient. Regarding payment decisions, Jung et al. (2016) use 16 field studies in a variety of settings to investigate how anchors can influence payments. Although their main conclusion confirms that anchoring occurs with and without financial consequences, they suggest that real payments may be less sensitive to anchoring.

Third, anchoring could matter in gambling decisions. For example, Johnson et al. (2009) analyze horserace betting and find that bettors excessively anchor on horses' barrier positions in prior race meetings but not on most recent race outcomes. They find bettors with greater levels of expertise to be less subject to anchoring, yet the significance of the effect prevails. Also studying horse racing, McAlvanah and Moul (2013) find that bookmakers fail to fully readjust odds when a horse is abruptly withdrawn (a late 
"scratch" in racing terminology). The initial odds emerge as a powerful anchor among economic agents with financial incentives and extensive experience. They find this effect to be economically meaningful, as bookmakers lose up to 20 percent of their profit margins because of insufficient adjustments.

In the following pages, we present results from studying anchoring in a game show setting. In the past, researchers employed data from game shows to investigate a wide range of behavioral characteristics. For instance, Gertner (1993) studies the degree of contestants' risk aversion in the show Card Sharks. Similarly, Post et al. (2008) analyze decision-making under risk in the show Deal or No Deal?. Metrick (1995) uses data from the Final Jeopardy! round to study whether contestants wager rationally (i.e., in a form consistent with a strategic best response), which is closely related to our own setting. ${ }^{6}$ However, Metrick (1995) does not focus on anchoring.

Our study aims to enrich our understanding of anchoring in testing whether such dynamics can also be detected in a game show environment where a wagering decision $(i)$ has to be made within seconds, (ii) involves risk, and (iii) can carry substantial financial consequences. A particular strength of our study comes from our rich sample, which includes 32 years of data for 6,064 contestants, which allows us to control for player-fixed effects.

\section{Data and Methodology}

\subsection{Jeopardy!}

\subsubsection{The Show}

In September 1984, the game show Jeopardy! began its run on US television. Remaining on air today, Jeopardy! has become the second-most popular show in syndication, averaging 25 million weekly viewers (Jeopardy!, 2015). ${ }^{7}$ Each episode features three contestants and three rounds: the Jeopardy! round with 30 clues, the Double Jeopardy! round with 30 clues, and the Final Jeopardy! round with one clue. The Double Jeopardy! round differs from the Jeopardy! round in that all clue values are doubled and clues are generally more difficult (Trebeck and Barsocchini, 1990). In both rounds, six categories with five clues each are available. Until November 26, 2001, the Jeopardy! round consisted of the clue values $\$ 100$, $\$ 200, \$ 300, \$ 400$, and $\$ 500$, whereas the Double Jeopardy! round featured the values $\$ 200, \$ 400, \$ 600$, $\$ 800$, and $\$ 1,000$. Since then, all clue values have been doubled.

\footnotetext{
${ }^{6}$ Other questions that have been analyzed using data from game shows relate to discriminatory behavior (e.g., Levitt, 2004, and Antonovics et al., 2005, use data from The Weakest Link), cooperation (e.g., Van den Assem et al., 2012, analyze data from Golden Balls), and gender differences in performance and risk preferences using Jeopardy! data (e.g., He et al., 2008, Lindquist and Säve-Söderbergh, 2011, Boyle and Shapira, 2012, Säve-Söderbergh and Lindquist, 2016, and Jetter and Walker, 2017).

${ }^{7}$ The most popular television show in syndication is Wheel of Fortune, drawing more than 30 million viewers per week. The show has been airing since 1983 (see Wheel of Fortune, 2016).
} 
Contrary to most game shows, the host (Alex Trebek) announces 'clues' and whoever is first to press the buzzer has to pose the correct question. Nevertheless, throughout the paper, we will use the terms of 'responding' or 'answering' to clues to facilitate readability. For any ordinary clue, the first one to correctly respond receives the associated monetary value which is added to their balance, and is allowed to select the next clue. However, if a contestant's answer is incorrect, they will have the dollar value of the clue subtracted from their account balance, and the other contestants will have the opportunity to respond. The contestant with the highest score at the end of the episode receives their account balance as prize money and returns for the next episode, while the second and third place contestants receive consolation prizes. Overall, the average winner in our sample earns US $\$ 19,752$.

\subsubsection{Daily Double Clues}

Our analysis focuses on a particular type of clue that appears three times in every episode (once in the Jeopardy! round and twice in Double Jeopardy!): Daily Double (DD) clues. These clues are hidden on the board, and whoever unknowingly selects a $D D$ clue is able to wager up to their entire account balance if they correctly respond to the next clue (see Trebeck and Barsocchini, 1990). More precisely, the Jeopardy! rules state that a player can wager up to their entire account balance or the largest dollar value on the current board, whichever value of the two is larger. Contrary to regular clues, $D D$ clues are only open to the contestant who happens to select these clues, and not to opponents.

An example board from the show is depicted in Table 1, where a contestant (Sally) happened to select a $D D$ clue in the episode aired on June 20,2016 . Sally selected Fonts for $\$ 1,600$, which turned out to be a $D D$ clue, and she decided to wager $\$ 1,500$. Note that the initial value of the question is made salient instantaneously before the wagering decision, as the contestant has to verbally state the initial dollar value of the clue ("I take Fonts for $\$ 1,600$ !"). Quite intuitively, the idea that the anchor is more powerful if made salient right before the corresponding decision has been highlighted by a number of studies, such as Critcher and Gilovich (2008).

Following the example displayed in Table 1, we briefly outline the sequence of events for $D D$ clues:

1. A player (in this case Sally) correctly responds to a clue.

2. Sally chooses "Fonts for $\$ 1,600$ " as the next clue.

3. It is revealed that "Fonts for $\$ 1,600$ " is a $D D$ clue.

4. Sally chooses how much to wager on correctly responding to the clue hidden behind "Fonts for $\$ 1,600$." At this point, she only knows the category but not the clue.

5. Sally wagers her desired amount up to her entire account balance (here $\$ 4,800$ ). If her account balance is less than the maximum value on the board $(\$ 1,000$ in the Jeopardy round; $\$ 2,000$ in the Double Jeopardy round), she can wager up to that maximum amount. In this case, Sally wagers $\$ 1,500$. 
Table 1: Show \#7,326, Double Jeopardy! round on June 20, 2016. Sally selected Fonts for $\$ 1,600$, which happened to be a $D D$ clue, and wagered $\$ 1,500$. She answered the clue correctly, raising her balance from $\$ 4,800$ to $\$ 6,300$. Another $D D$ clue was hidden under the category World Piece for $\$ 1,600$.

\begin{tabular}{cccccc}
\hline \hline & & & & \\
ISTHMUS & FONTS & THE & 12 & WORLD & IN THE \\
BE YOUR & & BILLBOARD & LETTER & PIECE & ---- OF \\
LUCKY DAY & & ALL-TIME HOT 100 & WORDS & & BATTLE \\
& & & & & \\
\hline & & & & 400 & 400 \\
& & & 800 & 800 & 800 \\
1600 & 1200 & 1200 & 1200 & 1200 \\
2000 & 1600 & 2000 & 1600 & 1600 & 1600 \\
& 2000 & & 2000 & 2000 & 2000 \\
\hline \hline
\end{tabular}

6. The clue is revealed. In this case, the clue is this: "The name of this popular font is from the Latin for runner".

7. Sally responds. If she is correct, she wins the wagered amount (i.e., moving from $\$ 4,800$ to $\$ 6,300$ ). If not, she loses the wagered amount (i.e., dropping to \$3,300). In this case, Sally responded correctly ("What is Courier?").

8. Sally selects the next clue, which is open for all competitors to buzz in again - unless it happens to be another $D D$ clue.

Theoretically, neither the Jeopardy! rules (see Trebeck and Barsocchini, 1990) nor popular Jeopardy! strategies would suggest a rational reason for why the initial dollar amount of the clue should systematically be related to the actual wager. ${ }^{8}$ In particular, the difficulty of the $D D$ clue is not related to the initial dollar amount under which the clue is hidden. ${ }^{9}$ Nevertheless, even if that was the case, rationality would dictate contestants to wager more on $D D$ clues hidden under lower dollar amounts and vice versa. For example, if a $D D$ clue hidden under $\$ 1,600$ was more difficult than a $D D$ clue hidden under $\$ 400$, a rational response would be to wager more on the latter clue, not less. Thus, if anything, ascribing the difficulty of the clue to the initial dollar value would introduce a negative bias for a potential relationship between the initial dollar value and the wagered amount. More generally, Section 5.2 investigates whether an alternative hypothesis based on potentially rational game strategies is able to explain our findings.

\footnotetext{
${ }^{8}$ For a number of Jeopardy! strategies, we refer to Ken Jenning's website (http://www.ken-jennings.com/faq), who is by far the most successful Jeopardy! contestant in history, or online forums, such as quora (https://www.quora.com/ What-are-the-best-ways-to-prepare-to-be-a-contestant-on-Jeopardy).

${ }^{9} \mathrm{~A}$ recent quote by one of the show's writers supports this claim. According to her, a $D D$ clue is more like a Final Jeopardy clue in difficulty, rather than the regular round questions from the Jeopardy! or Double Jeopardy! rounds. "A Daily Double is supposed to be like a "Final Jeopardy!." It's supposed to be something that requires a little more thought, requires a two-step process" (McCown, 2015).
} 


\subsubsection{Our Sample}

To analyze contestants' behavior in $D D$ clues, we access the $J !$ Archive, a fan-created website of Jeopardy! episodes. Employing a data specialist, we extracted all information from all available episodes. ${ }^{10}$ As of June 5, 2015, the website contains full information for 4,270 complete adult episodes, and initially, the sample includes 8,169 players. However, 2,105 players never hit a $D D$ clue, which means that our sample includes 6,064 players who took at least one $D D$ clue (39.69 percent female) and an overall number of $12,596 D D$ clues. Thus, on average, our sample contains $2.08 D D$ clues per player.

For each episode, the website lists all three contestants' full names, their accumulated prize money in every clue, the category of the clue, the sequence of clues, and the value of each clue. Furthermore, first names allow us to conjecture player gender. ${ }^{11}$ This rich sample allows us to control for a list of covariates that could independently affect the wagering decision, as well as individual-level fixed effects.

\subsection{Methodology}

Our empirical strategy follows an ordinary least squares approach, where we first estimate a univariate regression of the initial dollar value predicting the wagered amount in the $D D$ clue. We then move to a more complete framework, estimating the wager for $D D$ clue $c$ by player $i$ with

$$
\text { Wager }_{c, i}=\alpha_{0}+\alpha_{1} \text { Value }_{c}+\boldsymbol{X}_{\boldsymbol{c}, \boldsymbol{i}} \alpha_{2}+\boldsymbol{Z}_{\boldsymbol{i}} \alpha_{3}+\epsilon_{c, i} .
$$

Value $_{c}$ represents the initial dollar value of the clue, and we interpret a positive and statistically significant value of $\alpha_{1}$ as evidence consistent with the anchoring hypothesis. The vector $\boldsymbol{X}_{\boldsymbol{c}, \boldsymbol{i}}$ incorporates the following control variables: the maximum possible wager of player $i$ (given by their current account balance or the maximum value on the board), the score distance to the best opponent (own score minus score of best opponent), binary indicators for STEM categories (science, technology, engineering, and mathematics), the 20 most common clue categories of the show, and a binary gender indicator, as well as a daily time trend since the beginning of the show on September 10, 1984 (linear and squared). ${ }^{12}$ In addition, we control for the number of $D D$ clues a player has drawn over their previous career and a

\footnotetext{
${ }^{10}$ Note that the website does not include all Jeopardy! episodes. Every episode since January 5, 2004, is included, but the website occasionally misses episodes from earlier seasons. After checking the episode numbers and available data, we did not find evidence of systematic omissions from the archive. Nevertheless, our findings are consistent when analyzing only data since January 5, 2004, after which all episodes are available.

${ }^{11}$ Usually, names are commonly attributable to a gender (e.g., Isabel and Susan are female; James and John are male), and if a name could indicate either gender, a Google search for the full name readily produces a picture of the Jeopardy! contestant. The same logic applies for abbreviated first names (e.g., A.C.).

${ }^{12}$ We browsed all categories, manually sorting them into STEM and non-STEM. Examples of STEM-related categories are Botany, Insects, and Science $\mathcal{E}$ Nature. The 20 most common categories are Science, Before $\mathcal{G}$ After, Literature, Potpourri, American History, World History, Sports, Business 86 Industry, World Geography, U.S. Cities, Colleges 85 Universities, Animals, Transportation, Religion, U.S. Geography, Opera, Authors, People, Food, and The Bible.
} 
measure for the number of shows a player has participated in to date.

Including these control variables aims to isolate anchoring from other, potentially interfering dynamics. The maximum wager provides a natural limit on how much a contestant can wager, and, therefore likely constitutes an important parameter to consider when making wagering decisions. Similarly, a player's balance relative to the best opponent can include meaningful information when deciding one's wager, as leaders may bet more cautiously to preserve their lead, whereas trailing candidates may choose to take more risk to catch leaders. Binary indicators for STEM clues and the most common categories are intended to capture the influence of particular topics on wagering decisions (e.g., see Jetter and Walker, 2017). Furthermore, women have been shown to take on less risk in $D D$ wagering decisions on average (Jetter and Walker, 2017). A general time trend ensures that our results are not driven by a systematic change in wagering behavior over time. Finally, controlling for a player's previous $D D$ clues and episodes acknowledges that players may learn over time and adjust their wagering behavior. In particular, experience and expertise have been highlighted as potential drivers of anchoring (e.g., see Englich et al., 2005, 2006, Englich and Soder, 2009, and Mussweiler et al., 2000). Section 5 will consider such dynamics in detail. Finally, $\boldsymbol{Z}_{\boldsymbol{i}}$ indicates player-fixed effects, and $\epsilon_{c, i}$ constitutes the usual error term. ${ }^{13}$ Standard errors are clustered on the player level in all our regressions.

\section{Empirical Findings}

\subsection{Descriptive Statistics}

Distinguishing between the Jeopardy! and the Double Jeopardy! round, both before and after clue values were doubled (on November 26, 2001), Figure 1 visualizes wagers in relation to the initial dollar amount in four distinct graphs. Specifically, we graph the share of wagers by the number of 'steps' away from the respective initial dollar value. For example, if values are $\$ 100, \$ 200, \$ 300, \$ 400$, and $\$ 500$, one step constitutes $\$ 100$. The corresponding bars show the share of wagers occurring within the associated bin. The bar associated with zero steps away from the initial dollar value measures those wagers where the contestant has chosen to wager the exact amount of the initial dollar value. A bar that is, say, three steps away from zero indicates the share of wagers falling within two to three steps away from the initial dollar value.

Throughout the entire sample, approximately 29.3 percent of all wagers fall within one step of the initial dollar value. Furthermore, 1,349 of all 12,596 wagers (10.7 percent) constitute exactly the initial dollar value. Overall, the average wager exceeds the initial dollar value by $\$ 897$, indicating that contes-

\footnotetext{
${ }^{13}$ We use the $x t r e g$ command in Stata to estimate the fixed effects regressions.
} 
Jeopardy! round before $11 / 26 / 2001$ (34.2\% within 1 step)

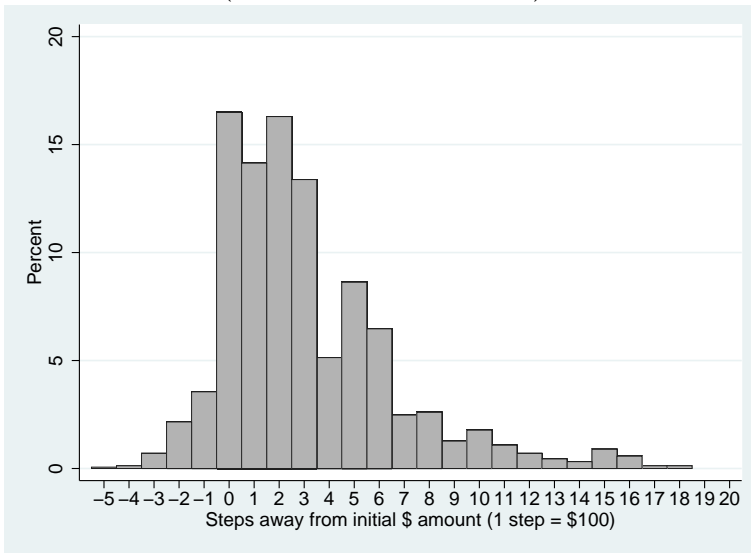

Jeopardy! round since $11 / 26 / 2001$ ( $29.2 \%$ within 1 step)

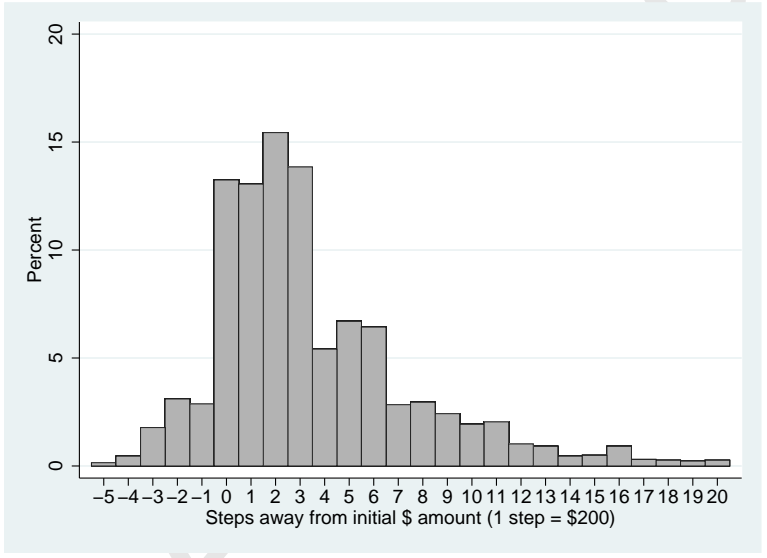

Double Jeopardy! round before $11 / 26 / 2001$ (29.8\% within 1 step)

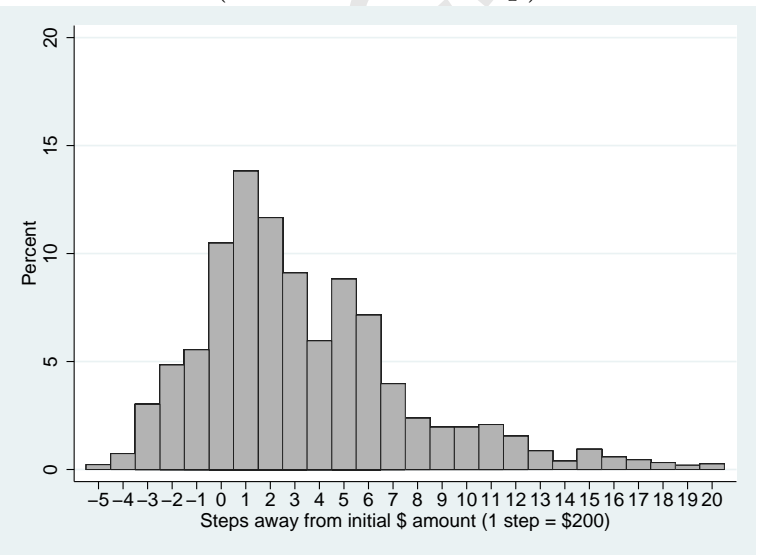

Double Jeopardy! round since 11/26/2001 (27.6\% within 1 step)

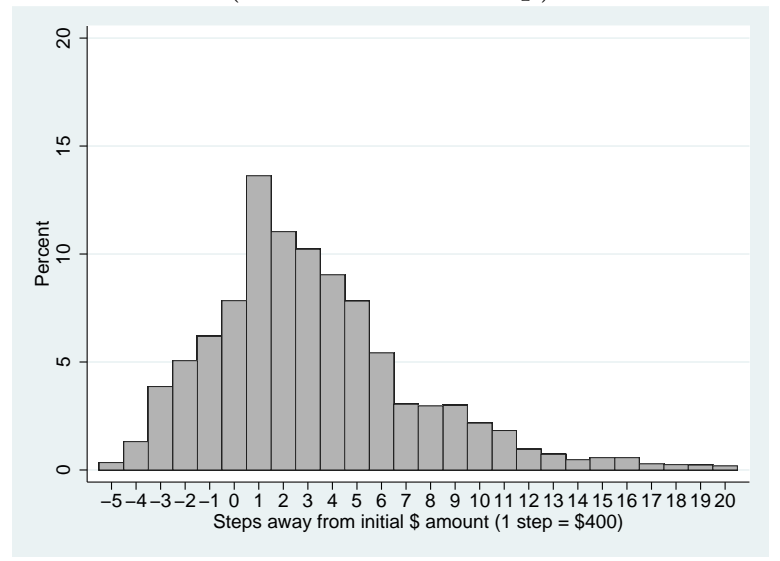

Figure 1: Wagering decisions in Daily Double clues in Jeopardy! and Double Jeopardy! rounds before and after the increase in prize money (November 26, 2001). One step is equivalent to one level dollar value difference between clues. The top one percentile is excluded in each graph to facilitate readability. 
tants, on average, prefer wagering more than the initial dollar value, rather than less. (The median wager exceeds the initial dollar value by $\$ 500$.)

To better understand wagering behavior for specific initial dollar amounts, Figure 2 visualizes the average wager across all four regimes (Jeopardy! and Double Jeopardy! round before and after the doubling in clue values) with the respective confidence intervals and median values, visualized by a black dot. Note that we omit $D D$ clues at the lowest clue value in each regime as they only occur one, nine, one, and five times within the respective regimes. ${ }^{14}$ Especially in the Jeopardy! round, we can notice a systematic upward trend of the average wager as the initial dollar amount increases. In Section 5, we will show that our results are consistent for both rounds, however.

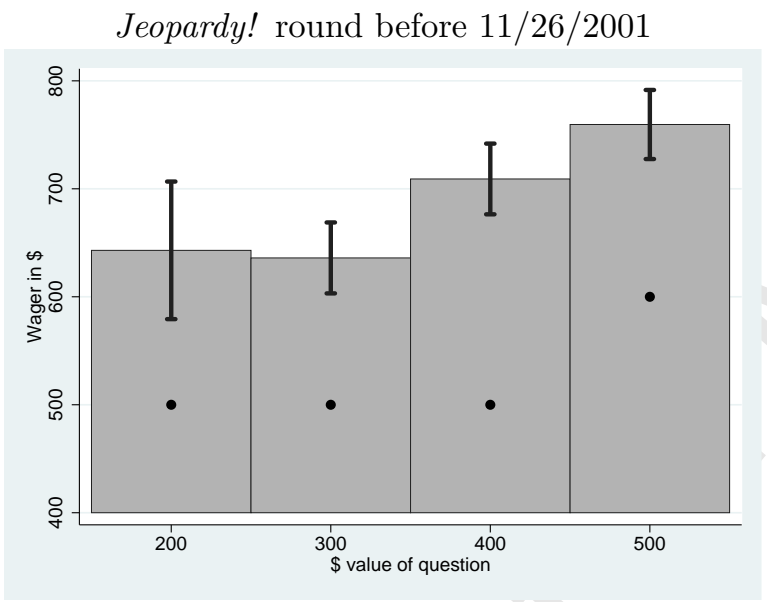

Jeopardy! round since $11 / 26 / 2001$

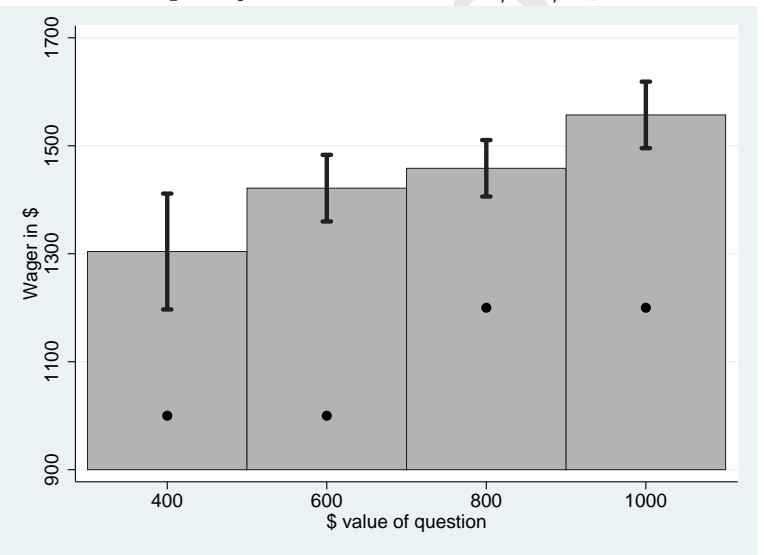

Double Jeopardy! round before 11/26/2001

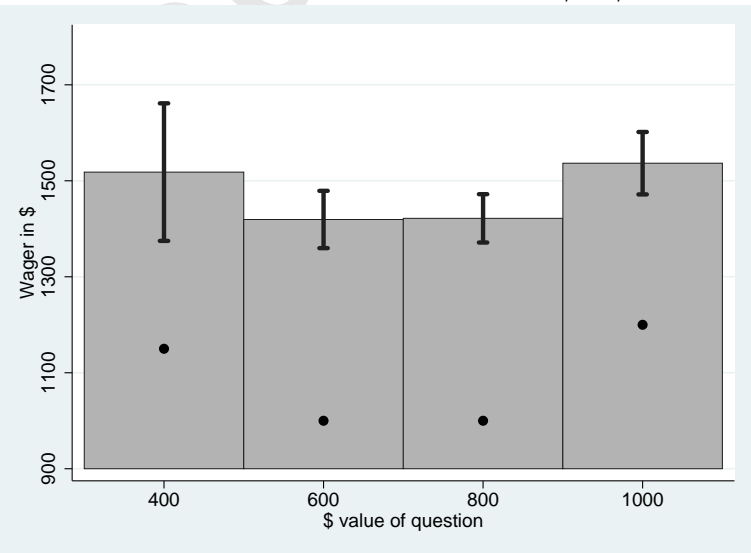

Double Jeopardy! round since 11/26/2001

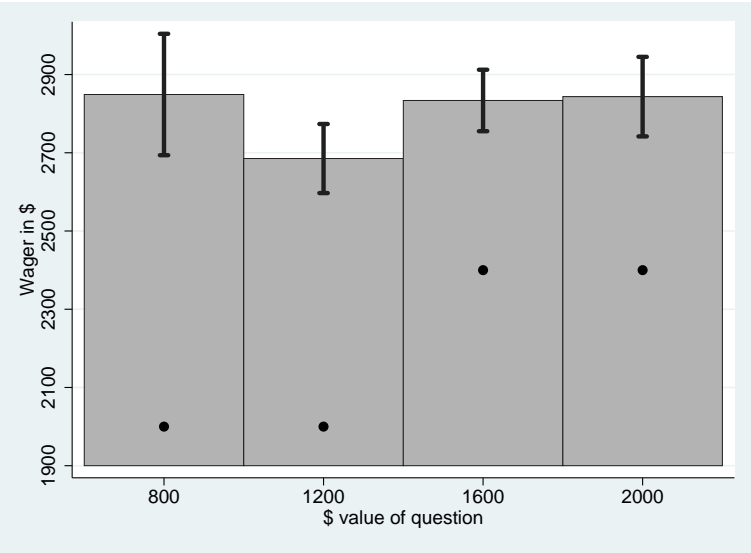

Figure 2: Average wagers by initial dollar amount of the respective clue with $95 \%$ two-sided confidence intervals. Black dots indicate the median wager.

\footnotetext{
${ }^{14}$ All our results are robust when excluding those values from the regression analysis. These results are available upon request.
} 
Table 2 presents summary statistics of the variables used in the main analysis. The minimum wager a player has placed ( $\$ 5$ ) appears 17 times, whereas the largest bet on a single $D D$ clue constitutes $\$ 18,000$ (Buddy Wright in the 2011 Tournament of Champions final game). ${ }^{15}$ These descriptive data also show that the average wager remains much closer to the initial dollar value than to the maximum possible wager. Furthermore, on average, the player drawing a $D D$ clue lags marginally (by $\$ 129$ ) behind their best opponent.

Additional insights from Table 2 reveal that, on average, a contestant has faced at least one $D D$ clue before, although over 65 percent of our sample observations are first-time $D D$ clues for the player. 39.7 percent of our $D D$ observations concern a female player. Finally, we list the 20 most common clue categories, which will be included in our most complete estimations. With these descriptive statistics in mind, we now move to our main regression results, investigating whether the initial dollar amount of the clue is predictive of the wagered amount and, if so, to what degree.

\subsection{Main Results}

Table 3 displays our main results, beginning with a univariate regression of the wagering amount on the initial dollar value. This estimation produces a positive coefficient of 1.348 that is significant at the one percent level. In quantitative terms, this would indicate that a $\$ 100$ rise in the initial dollar value relates to a $\$ 135$ increase in the wager. It is also interesting to see that the initial dollar value alone is able to explain more than 19 percent of the statistical variation in wagering decisions, as indicated by the adjusted $\mathrm{R}^{2}$.

Column (2) incorporates two control variables that are directly related to the contemporary scores of the contestant. First, the maximum wager represents the balance of the contestant or the highest dollar value on the board, whichever value is greater. This variable provides a natural limit to the player's wagering options and, therefore, constitutes an important constraint. Furthermore, the score distance to the best opponent captures the idea that the ultimate goal of winning a Jeopardy! episode entails edging out the other contestants. Once these regressors are accounted for, the coefficient of interest drops to a value of 0.397 but remains comfortably significant at the one percent level.

In column (3), we include binary indicators for STEM clues and the 20 most common Jeopardy! categories. However, their inclusion leaves the coefficient derived for the initial dollar value virtually unchanged. Furthermore, columns (4) and (5) include each player's Jeopardy! history with their previous $D D$ s and episodes, as well as a gender dummy and a time trend (measured as days since September 10,

\footnotetext{
${ }^{15}$ Note that all our results are virtually identical when excluding tournament games, which constitute matches with long-running champions and big money winners from the past season.
} 
Table 2: Summary statistics of all $12,596 D D$ clues for the full sample.

\begin{tabular}{|c|c|c|c|c|}
\hline Variable & Mean & (Std. Dev.) & Min. & Max. \\
\hline Wager in $\$$ & 1,924 & $(1,519)$ & 5 & 18,000 \\
\hline Initial $\$$ amount & 1,026 & $(494)$ & 100 & 2,000 \\
\hline Maximum wager $^{a}$ & 5,966 & $(4,973)$ & 500 & 39,000 \\
\hline Score distance to best opponent ${ }^{b}$ & -129 & $(5,190)$ & $-37,100$ & 35,600 \\
\hline STEM clue & 0.069 & $(0.253)$ & 0 & 1 \\
\hline \# of $D D$ 's before & 2.257 & $(2.291)$ & 1 & 38 \\
\hline \# of show for player & 2.055 & $(3.304)$ & 1 & 84 \\
\hline Female & 0.397 & $(0.489)$ & 0 & 1 \\
\hline Science category & 0.003 & $(0.058)$ & 0 & 1 \\
\hline American History category & 0.003 & $(0.053)$ & 0 & 1 \\
\hline Literature category & 0.003 & $(0.053)$ & 0 & 1 \\
\hline World History category & 0.003 & $(0.053)$ & 0 & 1 \\
\hline U.S. Cities category & 0.003 & $(0.050)$ & 0 & 1 \\
\hline Opera category & 0.002 & $(0.050)$ & 0 & 1 \\
\hline World Geography category & 0.002 & $(0.049)$ & 0 & 1 \\
\hline Word Origins category & 0.002 & $(0.048)$ & 0 & 1 \\
\hline Colleges \& Universities category & 0.002 & $(0.045)$ & 0 & 1 \\
\hline U.S. Geography category & 0.002 & $(0.045)$ & 0 & 1 \\
\hline The Bible category & 0.002 & $(0.040)$ & 0 & 1 \\
\hline Religion category & 0.001 & $(0.038)$ & 0 & 1 \\
\hline Authors category & 0.001 & $(0.036)$ & 0 & 1 \\
\hline Sports category & 0.001 & $(0.036)$ & 0 & 1 \\
\hline People category & 0.001 & $(0.034)$ & 0 & 1 \\
\hline Business \& Industry category & 0.001 & $(0.032)$ & 0 & 1 \\
\hline Before \& After category & 0.001 & $(0.030)$ & 0 & 1 \\
\hline Animals category & 0.001 & $(0.027)$ & 0 & 1 \\
\hline Food category & 0.001 & $(0.024)$ & 0 & 1 \\
\hline Potpourri category & 0.000 & $(0.013)$ & 0 & 1 \\
\hline
\end{tabular}

Notes: ${ }^{a}$ The current balance of the player or the highest clue value on the board, whichever value is greater. ${ }^{b}$ Score of player minus score of best opponent. 
Table 3: Main results from OLS regressions, estimating the $\$$ amount wagered in Daily Double clue.

\begin{tabular}{|c|c|c|c|c|c|c|}
\hline Dependent variable: Wager in $\$$ & (1) & $(2)$ & (3) & (4) & $(5)$ & (6) \\
\hline Initial $\$$ amount & $\begin{array}{c}1.348^{* * *} \\
(0.028)\end{array}$ & $\begin{array}{c}0.397^{* * *} \\
(0.040)\end{array}$ & $\begin{array}{c}0.395^{* * *} \\
(0.040)\end{array}$ & $\begin{array}{c}0.391^{* * *} \\
(0.039)\end{array}$ & $\begin{array}{c}0.232^{* * *} \\
(0.043)\end{array}$ & $\begin{array}{c}0.291^{* * *} \\
(0.057)\end{array}$ \\
\hline Maximum wager & & $\begin{array}{c}0.166^{* * *} \\
(0.006)\end{array}$ & $\begin{array}{c}0.166^{* * *} \\
(0.006)\end{array}$ & $\begin{array}{c}0.167^{* * *} \\
(0.006)\end{array}$ & $\begin{array}{c}0.165^{* * *} \\
(0.006)\end{array}$ & $\begin{array}{c}0.150^{* * *} \\
(0.007)\end{array}$ \\
\hline $\begin{array}{l}\text { Score distance to } \\
\text { best opponent }\end{array}$ & & $\begin{array}{c}-0.085^{* * *} \\
(0.005)\end{array}$ & $\begin{array}{c}-0.085^{* * *} \\
(0.005)\end{array}$ & $\begin{array}{c}-0.083^{* * *} \\
(0.005)\end{array}$ & $\begin{array}{c}-0.082^{* * *} \\
(0.005)\end{array}$ & $\begin{array}{c}-0.096^{* * *} \\
(0.006)\end{array}$ \\
\hline $\begin{array}{l}\text { Fixed effects for } 20 \text { most common } \\
\text { categories and STEM clues }\end{array}$ & & & yes & yes & yes & yes \\
\hline \# of $D D$ 's before & & & & $\begin{array}{l}-20.665 \\
(15.739)\end{array}$ & $\begin{array}{l}-16.378 \\
(14.795)\end{array}$ & $\begin{array}{l}-39.013^{*} \\
(20.179)\end{array}$ \\
\hline \# of show for player & & & & $\begin{array}{c}37.677^{* * *} \\
(13.244)\end{array}$ & $\begin{array}{c}32.972^{* * *} \\
(10.987)\end{array}$ & $\begin{array}{c}48.344^{* * *} \\
(17.979)\end{array}$ \\
\hline Female & & & & $\begin{array}{c}-52.492^{* *} \\
(26.053)\end{array}$ & $\begin{array}{c}-75.679^{* * *} \\
(25.762)\end{array}$ & \\
\hline Time trend & & & & & yes & yes \\
\hline Player-fixed effects & & & & & & yes \\
\hline \# of players & 6,064 & 6,064 & 6,064 & 6,064 & 6,064 & 6,064 \\
\hline \# of years & 32 & 32 & 32 & 32 & 32 & 32 \\
\hline$N$ & 12,596 & 12,596 & 12,596 & 12,596 & 12,596 & 12,596 \\
\hline Adjusted $R^{2}$ & 0.192 & 0.300 & 0.300 & 0.303 & 0.312 & 0.245 \\
\hline
\end{tabular}

Notes: Standard errors clustered on the player level are displayed in parentheses. ${ }^{*} p<0.10,{ }^{* *} p<0.05,{ }^{* * *} p<0.01$. 
1984). Throughout all these regressions, the relationship between the initial dollar value and the wager remains statistically significant at the one percent level.

Column (6) displays coefficients from incorporating player-fixed effects into our regression framework. Thus, the coefficient on the initial dollar value only captures within-player variation, as players with only one observation in our sample are perfectly identified by their respective fixed effects. These fixed effects control for any unobservable individual characteristics that are not captured by our control variables, such as education and income levels, as well as Jeopardy!-specific knowledge and skills, and risk preferences. Even in this rather restrictive framework, the initial dollar value remains a positive and statistically powerful predictor of the wager. In quantitative terms, an increase in the initial dollar value by $\$ 100$ is associated with a $\$ 29$ rise in the wager, everything else equal.

Finally, we also want to briefly discuss the derived coefficients of the main control variables. First, as expected, a larger maximum wager (i.e., a higher score) leads to a contestant wagering more, everything else equal. Somewhat understandably, a larger positive difference to the best opponent induces more conservative wagers, presumably because a contestant does not want to lose their lead in case of an incorrect answer. Second, contestants appear to wager more once they have won episodes and return to the show, potentially indicating more confidence in their Jeopardy!-specific abilities. Third, the significant gender effect in wagering behavior (columns 4 and 5) is consistent with the majority of the associated literature: on average, women tend to take less risk in wagering decisions compared with men. ${ }^{16}$ We will return to potential gender differences along the lines of anchoring shortly. For our upcoming robustness checks and extensions, we will refer to column (6) of Table 3 as our baseline estimation.

\section{Robustness Checks}

Although the results displayed in Table 3 are consistent with the phenomenon of anchoring, it is important to test whether these findings are robust to additional specifications and whether alternative explanations are possible. Tables 4 and 5 provide regression results from several estimations, which we now discuss.

\subsection{Alternative Specifications of Main Variables}

In Table 4, we begin with an alternative definition of our key variables. In particular, we take the natural logarithm of all variables involving a dollar value to ensure that outliers are not driving our findings. Moreover, the natural logarithm allows for an alternative interpretation of the derived

\footnotetext{
${ }^{16}$ For a related discussion, see Jianakoplos and Bernasek (1998), Byrnes et al. (1999), Eckel and Füllbrunn (2015), or Jetter and Walker (2017).
} 
magnitude in elasticities. Note that in the case of the score distance variable, we use the transformation of $\operatorname{Ln}(1+\$$ value $)$ to ensure that ties are preserved (i.e., when the score distance equals zero). Furthermore, for negative values, we calculate $-\operatorname{Ln}(1+\mid \$$ value $\mid)$. The corresponding results confirm our hypothesis, as the coefficient associated with the initial dollar amount remains positive and statistically significant at the one percent level. The respective magnitude indicates a doubling in the initial dollar amount relates to a 9.4 percent rise in the wager.

Table 4: Extensions and alternative explanations

\begin{tabular}{|c|c|c|c|c|c|c|c|}
\hline Dependent variable: & $\begin{array}{c}\text { Wager in } \$ \\
(1) \\
\text { Applying } \\
\text { logarithm }\end{array}$ & $\begin{array}{l}(2) \\
\text { Excluding } \\
\text { max. clue } \\
\text { values } \\
\end{array}$ & $\begin{array}{c}(3) \\
\text { Only } \\
\text { Jeopardy! } \\
\text { round }\end{array}$ & $\begin{array}{c}(4) \\
\text { Only Double } \\
\text { Jeopardy! round }\end{array}$ & $\begin{array}{c}(5) \\
\text { Out of } \\
\text { sequence }\end{array}$ & $\begin{array}{c}(6) \\
\text { In } \\
\text { sequence }\end{array}$ & (7) \\
\hline Ln(initial $\$$ amount) & $\begin{array}{c}0.094^{* * *} \\
(0.025)\end{array}$ & & & & & & \\
\hline Initial $\$$ amount & & $\begin{array}{c}0.252^{* * *} \\
(0.059)\end{array}$ & $\begin{array}{c}0.281^{* * *} \\
(0.055)\end{array}$ & $\begin{array}{c}0.166^{* * *} \\
(0.051)\end{array}$ & $\begin{array}{l}0.379^{*} \\
(0.201)\end{array}$ & $\begin{array}{c}0.298^{* * *} \\
(0.070)\end{array}$ & $\begin{array}{c}0.327^{* * *} \\
(0.087)\end{array}$ \\
\hline Sequential selection & & & & & & & $\begin{array}{l}-18.271 \\
(23.930)\end{array}$ \\
\hline $\begin{array}{l}\text { Sequential selection } \times \\
\text { initial } \$ \text { amount }\end{array}$ & & & & & & & $\begin{array}{l}-0.002 \\
(0.026)\end{array}$ \\
\hline Control variables ${ }^{a}$ & yes & yes & yes & yes & yes & yes & yes \\
\hline Player-fixed effects & yes & yes & & & yes & yes & yes \\
\hline \# of players & 6,064 & 5,515 & 3,478 & 5,044 & 2,104 & 5,327 & 6,064 \\
\hline \# of years & 32 & 32 & 32 & 32 & 32 & 32 & 32 \\
\hline$N$ & 12,596 & 10,509 & 4,220 & 8,376 & 2,828 & 9,768 & 12,596 \\
\hline Adjusted $R^{2}$ & 0.284 & 0.225 & 0.379 & 0.210 & 0.203 & 0.245 & 0.245 \\
\hline
\end{tabular}

Notes: Standard errors clustered on the player level are displayed in parentheses. ${ }^{*} p<0.10,{ }^{* *} p<0.05,{ }^{* * *} p<0.01 .{ }^{a}$ Includes the following variables: Maximum wager, score distance to best opponent, binary indicators for STEM clues and the 20 most common categories, the contestant's number of DD clues and Jeopardy! episodes, and a time trend. Columns (2) and (3) also include a binary gender indicator.

Column (2) addresses the fact that a natural limitation of one's wager is provided by the maximum possible wager. Thus, even if a player wanted to wager large sums of money, they are constrained by their current score, and it is possible that we simply do not observe actual wagering preferences in such cases. In column (2), we display results from excluding those observations where contestants have done exactly that - wager the maximum amount. However, we still observe a coefficient of interest that is consistent with the anchoring hypothesis, indicating that these maximum wagers are not driving our result. In additional estimations, we also employ Tobit models to test whether potential censoring of maximum wagers can drive our findings. All estimations confirm our results, as the coefficient of interest remains statistically significant at the one percent level. 


\subsection{Anchoring versus Strategic Considerations}

Columns (3) through (7) aim to test whether our findings are driven by particular elements of the show and whether strategic considerations could potentially explain our findings. Specifically, players may have already selected the dollar amount they wish to play for in their initial clue choice (e.g., "I take Fonts for $\$ 1,600 ! ")$, before the $D D$ status is even revealed. For example, if a player wants to play for $\$ 1,600$ in the upcoming clue - not $\$ 1,200$ or $\$ 2,000$ - and therefore selects a clue with that initial dollar amount, then the $D D$ opportunity could simply lead the player to confirm this preference. In this case, anchoring would not be the driving mechanism; rather, underlying strategic considerations would drive our results.

Although it remains difficult to systematically disentangle this mechanism from anchoring, we take several avenues to test whether such an alternative explanation is likely. First, if strategic concerns were driving the wagering decision, we would likely expect them to take place toward the end of an episode but less so in the initial Jeopardy! round. As both rounds consist of 30 clues each, it is difficult to argue that strategic concerns in, say, clue number ten in the first round would influence a player's wagering decision. In turn, such an explanation may appear more likely toward the end of the second round. ${ }^{17}$ Thus, as the end of the show approaches, one's goal of reaching a score higher than those of opponents becomes the predominant goal, whereas in early clues, one may be more concerned with maximizing one's balance, either to create the largest lead possible or to minimize distance to the opponents).

Following this logic, if strategic concerns could indeed explain our findings, we should be less likely to see the initial dollar value as a strong predictor of wagering decisions in early clues. Column (3) of Table 4 re-estimates our benchmark regression, this time only including $D D$ clues from the Jeopardy! round. Note that we exclude player-fixed effects for this estimation since this subsample only produces 1.2 clues per player on average (4,220 clues for 3,478 players). Here again, our baseline result is comfortably confirmed, suggesting that strategic considerations are unlikely to completely explain our findings. Column (4) shows that our results are also robust when only considering the Double Jeopardy! round.

Column (5) further considers the alternative hypothesis of strategic considerations, this time taking advantage of persistent patterns throughout the show. In particular, it is relatively common for players to sequentially "go through categories" by beginning with the lowest value and then subsequently working their way through higher value clues of that same category. ${ }^{18}$ This provides an additional piece of

\footnotetext{
${ }^{17}$ For instance, earlier work by Metrick (1995) systematically distinguishes among various game-theoretic scenarios in the Final Jeopardy! clue at the end of the show.

${ }^{18}$ For instance, consider the clue category Fonts from Table 1. If a player selects Fonts for $\$ 1,600$ directly after Fonts for $\$ 1,200$ was selected in the previous clue, this indicates a sequential progression through a clue category. However, if the player selects a different clue category (e.g., World Piece) or a clue value of Fonts that is not the next highest value (e.g., Fonts for $\$ 2,000$ ), we would consider this as somebody selecting "out of a sequence."
} 
information that allows us to identify those observations where strategic considerations are more likely. Specifically, if a player sequentially "goes through a category", it becomes less likely that they want to strategically play for a specific dollar value; rather, they move through the category in the traditional, mechanical way. In turn, if somebody selects out of a sequence, either by choosing a different category (even though the previously selected category still provides open clues) or by jumping values, it is more likely that a contestant consciously wishes to play for a specific dollar value in that upcoming clue.

Thus, we split the sample into those clues where the sequence is broken (i.e., moving out of a sequence) and those clues that are in line with a sequential progression. It is interesting to see that 77 percent of all $D D$ clues are selected in sequence, indicating a strong pattern for Jeopardy! players to follow that tradition. In terms of our results, however, we observe no differences: The familiar result emerges for either subsample and the coefficients of interest in these results are not statistically different from each other. Similarly, returning to the complete sample and introducing an interaction term between the initial dollar value and the number of previous clues that have been selected in sequence do not produce additional insights. The predictive power of the initial dollar value, however, prevails, as indicated by the results displayed in column (7).

Overall, these additional estimations cannot completely eliminate the possibility of unobservable strategic considerations driving our findings. It is possible that a player consciously selects a clue value because they want to play for exactly that amount, which would provide an alternative explanation for our findings. However, the corresponding results suggest that this hypothesis is unlikely able to explain our findings in their entirety, providing further evidence in favor of the anchoring hypothesis.

\subsection{Institutional Learning, Individual Experience, and Gender}

Beyond alternative explanations, we now check whether our result prevails across different time periods and players, with the corresponding results displayed in Table 5. For example, it is possible that a "learning phase" was necessary at the beginning of the show, in which contestants might have anchored on the initial dollar value for lack of a more refined game strategy. Thus, players today may be better prepared for wagering strategies, and we label such an evolution here "institutional learning". ${ }^{19}$

Specifically, we amend our most complete estimation by incorporating year-fixed effects in column (1). In column (2), we include an interaction term between the time trend and the initial dollar amount to test whether our core findings have changed over time. However, we recover the familiar result in both estimations, and the interaction term remains insignificant on conventional levels of statistical significance,

\footnotetext{
${ }^{19}$ An example for potential strategies can be found on Ken Jenning's website (http://www.ken-jennings.com/faq, by far the most successful Jeopardy! contestant in history) or in online forums, such as quora (https://www.quora.com/ What-are-the-best-ways-to-prepare-to-be-a-contestant-on-Jeopardy).
} 


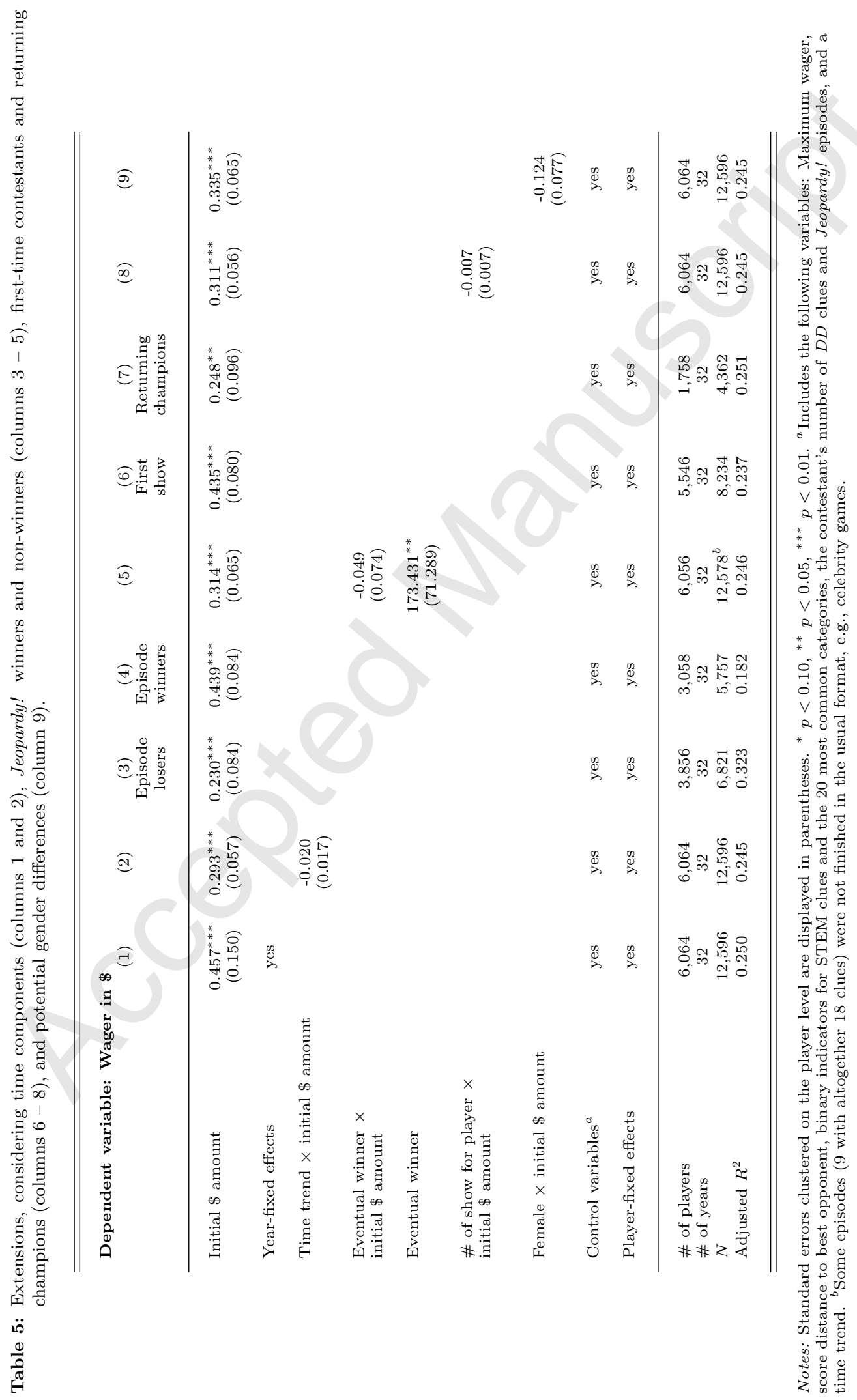


indicating that our result has been persistent throughout all 32 years of data.

Furthermore, beyond potential heterogeneity over time, it is possible that some players exhibit different anchoring patterns. In fact, experience has been found in a number of associated studies to influence anchoring behavior (e.g., Englich et al., 2005; Englich et al., 2006; Englich and Soder, 2009; Mussweiler et al., 2000). For example, in the Jeopardy! context, those contestants who do particularly well on the show may be less prone to anchoring. In columns (3) and (4), we distinguish between those contestants who ended up not winning their respective episodes and those who did. Most importantly, the effect prevails for either group and, if anything, is stronger in quantitative terms for winners (the coefficients on the initial dollar amount in columns 3 and 4 are marginally statistically different from each other at the ten percent level). However, when estimated in the full sample, an interaction term between winner and the initial dollar amount is not a statistically relevant predictor (see column 5). Thus, player success does not appear to be the driving force and the initial dollar amount remains a strong predictor of wagers by successful and unsuccessful Jeopardy! contestants alike.

In columns (6) and (7), we take advantage of our panel structure by distinguishing between observations of first-time Jeopardy! contestants and returning champions. But, here again, the effect is not driven by either group alone and introducing an interaction term between the number of shows a player has been on and the initial dollar amount does not produce notable heterogeneity (see results in column 8). Rather, the result appears to be prevalent for newcomers and established Jeopardy! veterans alike, suggesting that experience does not affect our findings in a meaningful way.

Finally, column (9) tests for potential gender differences by introducing an interaction term between the initial dollar amount and Female, but we find no evidence of systematic heterogeneity between women and men in our results. This finding in itself may be notable, in light of prior work finding gender differences in competitive behavior (although not heuristics) in Jeopardy! (see, for example, He et al., 2008, Lindquist and Säve-Söderbergh, 2011, Säve-Söderbergh and Lindquist, 2016, or Jetter and Walker, 2017).

\section{Conclusion}

This paper tests for anchoring in 12,596 wagering decisions of 6,064 contestants in Daily Double clues in the US game show Jeopardy!. Our study aims to complement the existing literature by investigating a real-life setting that provides a large sample and meaningful payoff scenarios.

Our results produce robust evidence supporting the hypothesis that people anchor their wagering decision on seemingly unrelated dollar values that have been made salient immediately prior to the wagering decision. The initial dollar amount of a clue emerges as a statistically powerful predictor of the wagering amount, and this result remains robust to the inclusion of a comprehensive list of control 
variables, time trends, time-fixed effects, and player-fixed effects. In terms of magnitude, our benchmark estimation suggests that a rise in the initial dollar amount by $\$ 100$ is associated with a $\$ 29$ increase in the wager.

We provide several robustness checks and extensions. One alternative explanation of our findings suggests that players consciously wish to play for a specific amount of money, and the opportunity to wager would simply reveal that desire. However, we find no evidence supporting that hypothesis since we recover the familiar result when $(i)$ considering wagers early on in the game (where strategic considerations are less likely to matter) and (ii) focusing on wagers that remain "in sequence" (when players sequentially move through a category from lower- to higher-value clues). Although these estimations cannot completely eliminate strategic considerations as an alternative hypothesis, the corresponding results further support an explanation that is consistent with anchoring. We then analyze whether institutional or individual 'learning' is taking place with respect to anchoring. Interestingly, we find no evidence of such heterogeneity: the effect emerges consistently over time (from 1984 to 2015) and prevails for both Jeopardy! newcomers and established veterans.

Overall, these findings can prove relevant for several real-life situations where anchoring could occur, such as investment or gambling decisions, negotiation processes, reference pricing for consumers, and online auctions. Anchoring may also carry implications for the risk-taking of CEOs and managerial personnel in financial institutions. Nevertheless, it is important to keep the scope of our study in mind, as both Jeopardy! contestants and the context of the show are not necessarily transferable to other settings. 


\section{References}

Agarwal, S., Chomsisengphet, S., Mahoney, N., and Stroebel, J. (2015). Regulating consumer financial products: Evidence from credit cards. The Quarterly Journal of Economics, 130(1):111-164.

Antonovics, K., Arcidiacono, P., and Walsh, R. (2005). Games and discrimination: Lessons from the weakest link. Journal of Human Resources, 40(4):918-947.

Ariely, D., Loewenstein, G., and Prelec, D. (2003). "Coherent arbitrariness": Stable demand curves without stable preferences. Quarterly Journal of Economics, 118(1):73-106.

Baker, M., Pan, X., and Wurgler, J. (2012). The effect of reference point prices on mergers and acquisitions. Journal of Financial Economics, 106(1):49-71.

Beggs, A. and Graddy, K. (2009). Anchoring effects: Evidence from art auctions. The American Economic Review, 99(3):1027-1039.

Bergman, O., Ellingsen, T., Johannesson, M., and Svensson, C. (2010). Anchoring and cognitive ability. Economics Letters, 107(1):66-68.

Boyle, E. and Shapira, Z. (2012). The liability of leading: Battling aspiration and survival goals in the Jeopardy! Tournament of Champions. Organization Science, 23(4):1100-1113.

Bucchianeri, G. W. and Minson, J. A. (2013). A homeowner's dilemma: Anchoring in residential real estate transactions. Journal of Economic Behavior \&J Organization, 89:76-92.

Byrnes, J. P., Miller, D. C., and Schafer, W. D. (1999). Gender differences in risk taking: A meta-analysis. Psychological Bulletin, 125(3):367.

Choi, J. J., Haisley, E., Kurkoski, J., and Massey, C. (2012). Small cues change savings choices. NBER Working Paper No. 17843.

Critcher, C. R. and Gilovich, T. (2008). Incidental environmental anchors. Journal of Behavioral Decision Making, 21(3):241-251.

Dougal, C., Engelberg, J., Parsons, C. A., and Van Wesep, E. D. (2015). Anchoring on credit spreads. The Journal of Finance, 70(3):1039-1080.

Eckel, C. C. and Füllbrunn, S. (2015). Thar she blows? Gender, competition, and bubbles in experimental asset markets. The American Economic Review, 105(2):906-920.

Englich, B., Mussweiler, T., and Strack, F. (2005). The last word in court - a hidden disadvantage for the defense. Law and Human Behavior, 29(6):705-722.

Englich, B., Mussweiler, T., and Strack, F. (2006). Playing dice with criminal sentences: The influence of irrelevant anchors on experts' judicial decision making. Personality and Social Psychology Bulletin, $32(2): 188-200$.

Englich, B. and Soder, K. (2009). Moody experts - how mood and expertise influence judgmental anchoring. Judgment and Decision Making, 4(1):41-50.

Frederick, S. (2005). Cognitive reflection and decision making. Journal of Economic Perspectives, 19(4):25-42.

Furnham, A. and Boo, H. C. (2011). A literature review of the anchoring effect. Journal of SocioEconomics, 40(1):35-42. 
Galinsky, A. D. and Mussweiler, T. (2001). First offers as anchors: The role of perspectivetaking and negotiator focus. Journal of Personality and Social Psychology, 81:657-669.

Gertner, R. (1993). Game shows and economic behavior: Risk-taking on "card sharks". Quarterly Journal of Economics, 102(2):507-521.

He, X., Inman, J. J., and Mittal, V. (2008). Gender jeopardy in financial risk taking. Journal of Marketing Research, 45(4):414-424.

Jeopardy! (2015). Show history. http://www.jeopardy.com/showguide/abouttheshow/showhistory/. Accessed: 2015-09-21.

Jetter, M. and Walker, J. K. (2017). The gender of your opponents: Explaining the gender gap in performance and risk-taking? Forthcoming in the European Economic Review.

Jianakoplos, N. A. and Bernasek, A. (1998). Are women more risk averse? Economic Inquiry, 36(4):620630 .

Johnson, J. E. V., Schnytzer, A., and Liu, S. (2009). To what extent do investors in a financial market anchor their judgments excessively? Evidence from the Hong Kong horserace betting market. Journal of Behavioral Decision Making, 22(4):410-434.

Jones, L. E., Loibl, C., and Tennyson, S. (2015). Effects of informational nudges on consumer debt repayment behaviors. Journal of Economic Psychology, 51:16-33.

Jung, M. H., Perfecto, H., and Nelson, L. D. (2016). Anchoring in payment: Evaluating a judgmental heuristic in field experimental settings. Journal of Marketing Research, 53(3):354-368.

Kaustia, M., Alho, E., and Puttonen, V. (2008). How much does expertise reduce behavioral biases? The case of anchoring effects in stock return estimates. Financial Management, 37(3):391-412.

Levitt, S. D. (2004). Testing theories of discrimination: Evidence from "weakest link". Journal of Law and Economics, 47(2):431-452.

Levitt, S. D. and List, J. A. (2007). What do laboratory experiments measuring social preferences reveal about the real world? The Journal of Economic Perspectives, 21(2):153-174.

Levitt, S. D. and List, J. A. (2008). Homo economicus evolves. Science, 319(5865):909-910.

Lindquist, G. S. and Säve-Söderbergh, J. (2011). "Girls will be girls", especially among boys: Risk-taking in the "Daily Double" on Jeopardy. Economics Letters, 112(2):158-160.

List, J. A. (2011). Does market experience eliminate market anomalies? The case of exogenous market experience. The American Economic Review, 101(3):313-317.

List, J. A. and Millimet, D. L. (2008). The market: Catalyst for rationality and filter of irrationality. The BE Journal of Economic Analysis \& Policy, 8(1).

McAlvanah, P. and Moul, C. C. (2013). The house doesn't always win: Evidence of anchoring among Australian bookies. Journal of Economic Behavior E Organization, 90:87-99.

McCown, A. (March 12, 2015). What's it like to be one of the jeopardy! writers? http://www.avclub.com/article/whats-it-be-one-jeopardy-clue-writers-216093. Accessed: 2015-12-28.

McHugh, S. and Ranyard, R. (2016). Consumers credit card repayment decisions: The role of higher anchors and future repayment concern. Journal of Economic Psychology, 52:102-114.

Metrick, A. (1995). A natural experiment in "Jeopardy!". The American Economic Review, 85(1):240-53. 
Meub, L. and Proeger, T. E. (2015). Anchoring in social context. Journal of Behavioral and Experimental Economics, 55:29-39.

Mussweiler, T., Strack, F., and Pfeiffer, T. (2000). Overcoming the inevitable anchoring effect: Considering the opposite compensates for selective accessibility. Personality and Social Psychology Bulletin, 26(9):1142-1150.

Post, T., van den Assem, M. J., Baltussen, G., and Thaler, R. H. (2008). Deal or no deal? Decision making under risk in a large-payoff game show. The American Economic Review, 98(1):38-71.

Säve-Söderbergh, J. and Lindquist, G. S. (2016). Children do not behave like adults: Gender gaps in performance and risktaking in a random social context in the high-stakes game shows Jeopardy and Junior Jeopardy. Forthcoming in The Economic Journal.

Stewart, N. (2009). The cost of anchoring on credit-card minimum repayments. Psychological Science, 20(1):39-41.

Trebeck, A. and Barsocchini, P. (1990). The Jeopardy Book. Harper Collins, New York, NY USA.

Tversky, A. and Kahneman, D. (1974). Judgment under uncertainty: Heuristics and biases. Science, 185(4157):1124-1131.

Van den Assem, M. J., Van Dolder, D., and Thaler, R. H. (2012). Split or steal? cooperative behavior when the stakes are large. Management Science, 58(1):2-20.

Wheel of Fortune (August 1, 2016). Wheel of Fortune. https://www.wheeloffortune.com/news-andevents/harry-friedman-world-record/. Accessed: 2016-08-01. 